\title{
Catalytic Cascade Reactions Inspired by Polyketide Biosynthesis
}

\author{
Daniel Moser, Alessandro Castrogiovanni, Dominik Lotter, Reto M. Witzig, Vincent C. Fäseke, \\ Felix C. Raps, and Christof Sparr*
}

\begin{abstract}
Aldol reactions belong to the most important methods for carbon-carbon bond formation and are also involved in one of the most astonishing biosynthetic processes: the biosynthesis of polyketides governed by an extraordinarily sophisticated enzymatic machinery. In contrast to the typical linear or convergent strategies followed in chemical synthesis, this late-stage catalysis concept allows Nature to assemble intermediates that are diversified into a broad range of scaffolds, which assume various crucial biological functions. To transfer this concept to small-molecule catalysis to access products beyond the natural systems, a stepwise approach to differentiate increasingly complex substrates was followed by investigating arene-forming polyketide cyclizations. An outline of our efforts to develop and apply these concepts are presented herein.
\end{abstract}

Keywords: Aldol condensation · Atropisomers · Biomimetic synthesis · Late-stage catalysis · Stereoselectivity

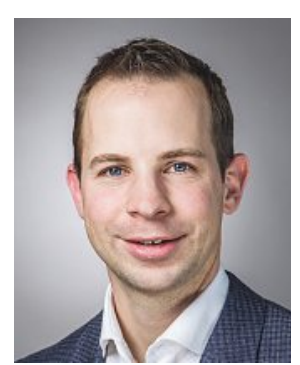

Christof Sparr received his $\mathrm{PhD}$ from the ETH Zurich working in the group of Prof. Ryan Gilmour and subsequently joined the groups of Prof. Dieter Seebach and Prof. Steven V. Ley. In 2013, Christof became habilitand mentored by Prof. Karl Gademann and since 2016, he is working as Assistant Professor at the University of Basel. He is recipient of the ETH silver medal, a SNSF starting grant, the Werner Prize of the Swiss Chemical Society 2017 and the Ruzicka Prize of the ETH Zurich 2018.

\section{Introduction}

Biomimetic cascade reactions fascinate chemists not only because of the drastically reduced number of synthetic steps required for generating molecular complexity, but also since they provide mechanistic insights that allow us to further understand the intricate interplay of biochemical processes. Bioinspired strategies were therefore studied for increasingly complex polycyclizations, which efficiently lead to otherwise inaccessible structural diversity.[1] Since the pioneering work by Eschenmoser ${ }^{[2]}$ and Stork, ${ }^{[3]}$ polyene cyclizations evolved to profoundly explored biomimetic cascade reactions, providing numerous terpene products with a low oxygenation degree. ${ }^{[4-7]}$ Following the seminal research on steroid synthesis, ${ }^{[8]}$ significant progress was thereby accomplished by mimicking terpene cyclases, culminating in highly efficient and innovative processes catalyzed by small organic molecules. ${ }^{[5-7,9]}$ Also the biosynthetic diversification of more oxidized precursors is close to perfection when it comes to bestowing different families of natural products with a defined oxygenation pattern. For instance, polyether natural products frequently used as antibiotic or anticancer agents, typically owe their structural complexity from epoxide opening cascades. Their structure is partially predefined in the assembly steps and the subsequent cyclization cascades provide further complexity. Elegant approaches were thus developed to guide selective polyether formation by

${ }^{\star}$ Correspondence: Prof. Dr. C. Sparr, E-mail: christof.sparr@unibas.ch

University of Basel, Department of Chemistry, St. Johanns-Ring 19, CH-4056 Basel chemical synthesis. ${ }^{[10-12]}$ Polycyclizations of substrates with an even higher degree of oxygenation provide a fascinating diversity of polyketide natural products, which are commonly assembled from acetate units. Aromatic polyketides are of pronounced importance in pharmaceutical research and enormous progress was achieved in investigating their biological activity and deciphering biosynthetic cascade reactions. ${ }^{[13-22]}$

In polyketide biosynthesis, the folding of the polyketide chains is precisely controlled in highly selective polyketide cyclizations, creating a broad range of aromatic polyketides such as the pharmaceutically relevant anthracyclines or tetracyclines (Scheme 1). ${ }^{[15,21]}$ Nevertheless, not only the differentiation of a remarkable number of reactive conformations, but also the high reactivity of the substrates render the development of a biomimetic, small-molecule catalyzed polyketide cyclization distinctly challenging. We thus approached this intriguing question by examining increasingly complex cyclizations. In our initial studies, which were summarized in an earlier Chimia article, ${ }^{[23]}$ we focused on cyclizations related to the biosynthesis of the atropisomeric natural product fasamycin C (Scheme 1, bottom), ${ }^{[24,25]}$ which is characterized by a rotationally restricted biaryl bond. Secondary amine-catalyzed aldol condensations thereby provided several distinct families of atropisomers by means of a stereoselective arene-formation, giving access to various well-defined molecular scaffolds. ${ }^{[26-29]}$

Atropisomeric architectures are routinely employed as catalysts in stereoselective transformations providing a wide range of indispensable products. Furthermore, rotationally restricted moieties with a suitable configurational stability are increasingly taken into consideration in drug discovery campaigns. ${ }^{[30]}$ Recently, the incorporation of multiple stereogenic axes was established as an inventive design step for drug candidates with a particularly well-defined structure. ${ }^{[31]}$

Since a defined spatial orientation of functional groups is crucial for designing bioactive compounds, tailored catalysts and molecular building blocks in general, atropisomeric compounds bearing several stereogenic axes are currently emerging as particularly promising core structures, as they allow the design of more complex and distinct molecular geometries. ${ }^{[32-34]}$ However, to selectively access atropisomeric multiaxis systems, the configuration of each stereogenic axis needs to be precisely controlled. ${ }^{[33]}$ In particular the selective formation of the unfavored stereoisomer 

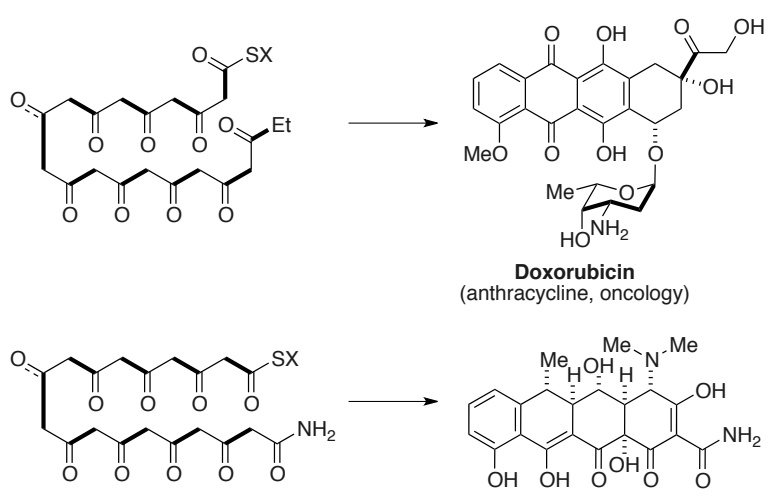

Doxycycline (tetracycline, antibiotic)<smiles>[X]C(=O)CC(=O)CC(=O)CC(=O)CC(=O)CC(=O)CC(=O)CC(=O)CC(=O)CC(=O)CC(=O)CC(C)=O</smiles>

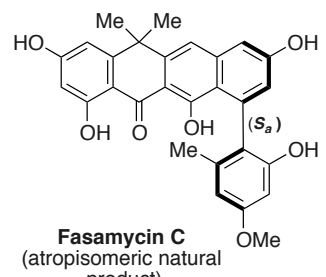

(atropisomeric na

Scheme 1. Folding and polycyclizations during the biosynthesis of the aromatic polyketides doxorubicin, doxycycline and fasamycin $\mathrm{C}$.

$\left(\mathrm{P}_{\mathrm{A}}\right)$ therefore requires a drastic lowering of the activation barrier $\left(\Delta \Delta \mathrm{G}^{\ddagger}\right)$ in order to overcome the substrate bias in the substratecatalyst mismatch scenario (Fig. 1).

Based on our previous findings for the atroposelective areneforming aldol condensation, ${ }^{[26,28]}$ we hence examined the catalystcontrolled stereodivergent synthesis of atropisomeric multiaxis systems. ${ }^{[33]}$ In the final steps, the building block addition to a ternaphthalene carbaldehyde was followed by an in situ oxidation and a first substrate-controlled aldol condensation revealed an intrinsic substrate preference of $86: 14$, indicating the significantly organized structure of the ternaphthalene substrate (Scheme 2). ${ }^{[35]}$ In order to override this preference and to invert selectivity, a cinchonidinium catalyst was utilized at lower temperature under otherwise identical conditions. This interesting finding highlights the efficiency of ion-pairing catalysis for the substrate-catalyst mismatch scenario in the stereodivergent synthesis of multiaxis systems.

Nonetheless, the substrate preference for the fourth stereogenic axis led to a remarkable 97:3 diastereoselectivity under substrate stereocontrol (Scheme 3). Extensive optimization studies uncovered that a combination of a Lygo-type catalyst with

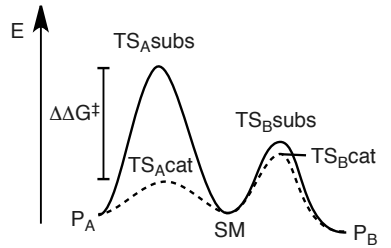

Fig. 1. The requirement of catalyst-controlled stereodivergent catalysis to overcome substrate bias in the substrate-catalyst mismatched scenario.

sodium hydride allows the inversion of selectivity to give the desired helically shaped diastereomer (d.r. $=77: 23$ ). Methods for diastereoselective catalysis were thus established to individually address each stereogenic axis of atropisomeric multiaxis systems with up to four stereogenic axes. Even in cases with a pronounced substrate preference, stereodivergent catalysis is feasible by the selection of a suitable catalyst for the desired diastereomeric atropisomer.

Gratifyingly, an excellent configurational stability and a uniquely compact helical secondary structure were first determined in solution and corroborated by crystallography. ${ }^{[36]}$ Arriving at entirely artificial polyaromatics with distinct molecular architectures after first considering polyketide natural products, therefore confirmed the virtues of transferring a biosynthetic concept to small-molecule catalysis. ${ }^{[22]}$ Moreover, the well-defined structures of the stereochemically defined oligo-1,2-naphthylenes with their polyketide pattern offered several fascinating applications. Together with the Wenger group, we thus explored photoinduced electron transfer (PET) processes through the secondary structure of the helical atropisomeric multiaxis systems. The dependence of the electron-transfer rate on oligomer length for different donoracceptor compounds as well as possible shortcuts were investigated after functionalizing the end groups of the oligomers (Fig. 2). In contrast to previous studies that usually involved linear model systems, ${ }^{[37]}$ multiple electron transfer pathways can now compete with each other. ${ }^{[38]}$ While PET through the covalent backbone of the helical structure is feasible, also a superposition with PET shortcuts through noncovalent contacts is possible. Interestingly, the measurements showed that the electronic coupling is unusually insensitive to bridge elongation, counter to those usually observed in linear systems. A possible rational for this observation is that the oligo-1,2-naphthylene scaffolds orient the substituents similar to tube-like objects. This will allow the electrons to depart from their circular path through covalent bonds, rendering a superposition with PET shortcuts feasible. ${ }^{[35,39]}$

Having observed a high degree of modularity with the iterative building block addition combined with a stereoselective arene-
Scheme 2. Catalyst-controlled synthesis of an atropisomeric stereotriad.

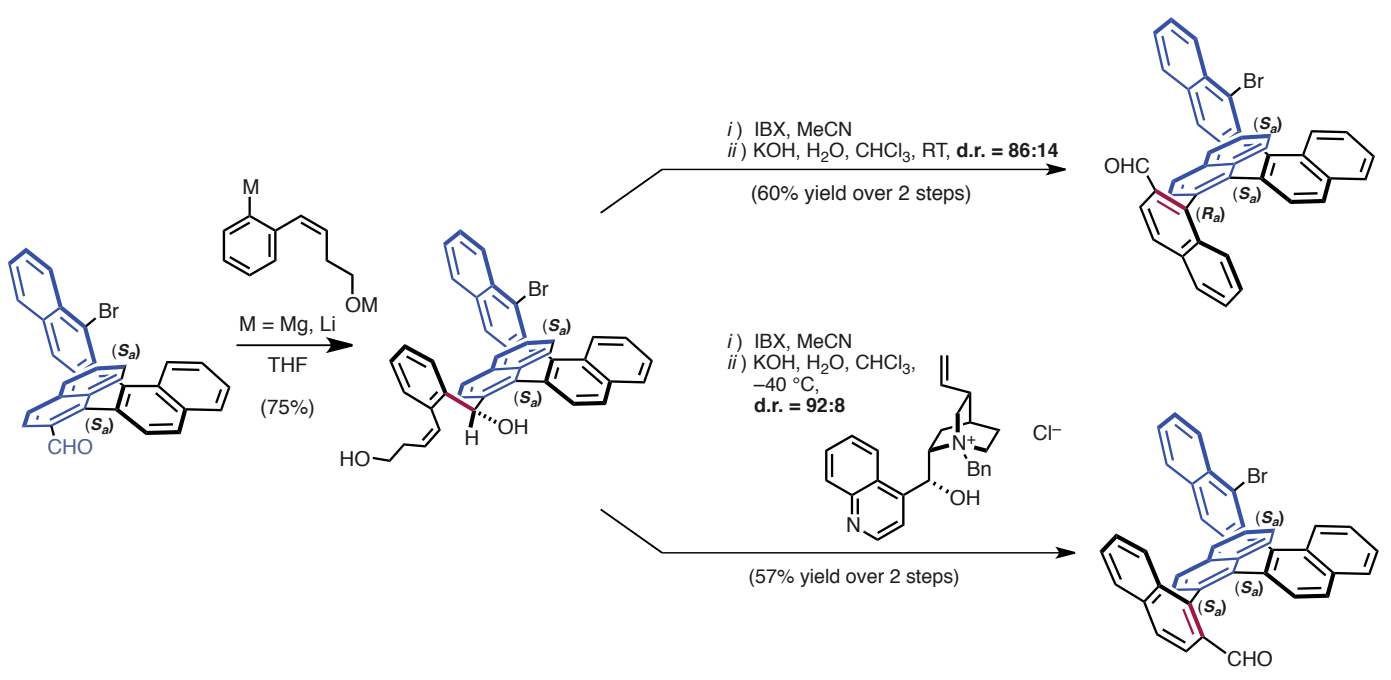




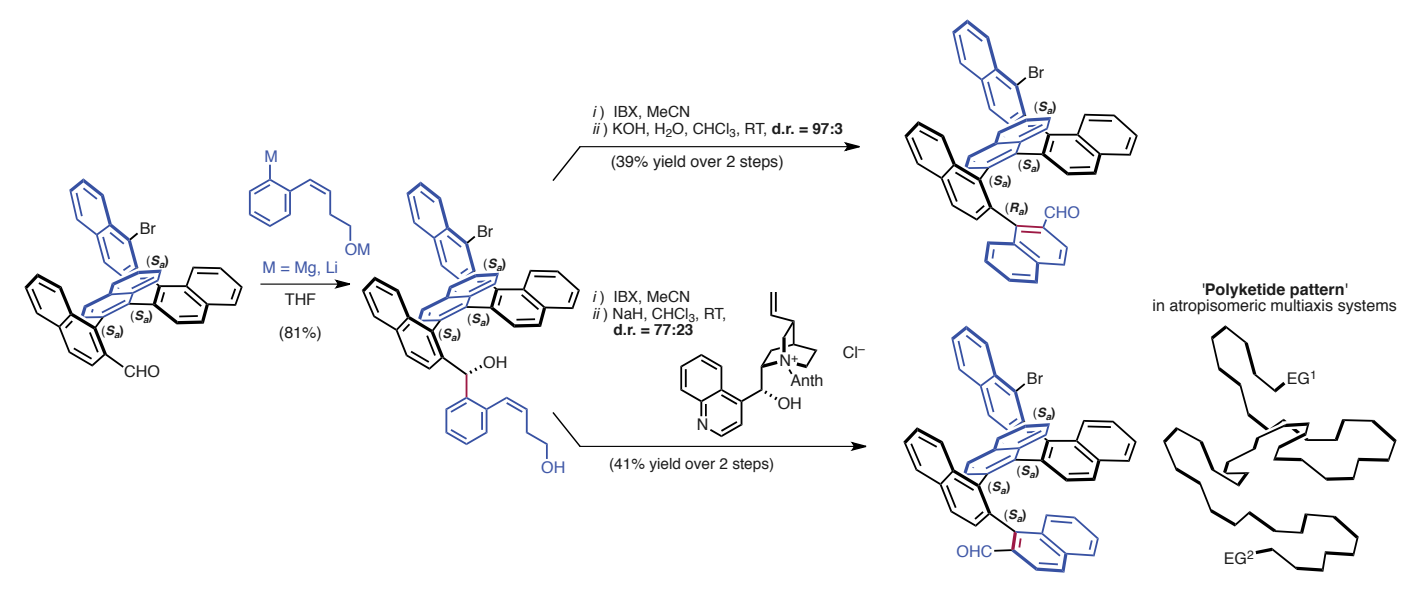

Scheme 3. Inverting a notable substrate bias by stereodivergent catalysis and the 'polyketide pattern' in helically-shaped atropisomeric multiaxis systems. EG: end group

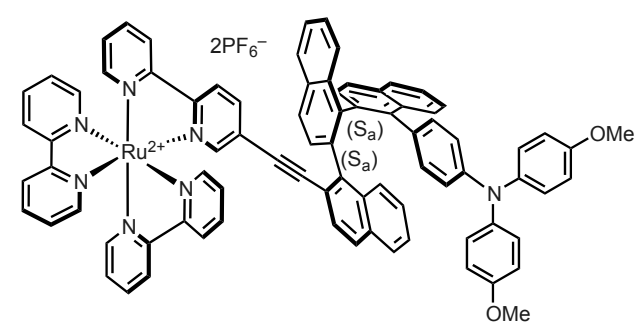

Fig. 2. Spatial organization of donor-acceptor compounds to study electron transfer through the secondary structure of oligo-1,2-naphthylenes.

forming aldol condensation, we next assessed the well-defined topology of the explored atropisomers for the design of a new class monophosphine ligands named JoyaPhos (Scheme 4). ${ }^{[40]}$ The synthesis of the JoyaPhos ligands commences by the building block addition $^{[28,41]}$ to 2-bromobenzaldehyde. After an in situ oxidation and a stereoselective arene-forming aldol condensation, a subsequent functional group interconversion provided the enantiomerically enriched carboxylic acid ester with an 99:1 enantiomeric ratio, which serves as optimal precursor for an ester-to-anthracene transformation which we previously developed. ${ }^{[42]}$ With this chain termination strategy, an atropisomeric teraryl bromide was obtained as common intermediate for the preparation of monodentate diarylteraryl- and dialkylterarylphosphines with different steric and electronic properties. Bromine-lithium exchange was followed by treatment of the resulting organolithium species with the corresponding chlorophosphines to provide different JoyaPhos monophosphines, such as $\mathrm{Cy}_{2}$ JoyaPhos. We subsequently evaluated the performance of several JoyaPhos ligands and found that the asymmetric allylic alkylation of (E)-1,3-diphenylallyl acetate with dimethyl malonate at ambient temperature under standard conditions provides the desired product in nearly quantitative yield and an enantiomeric ratio of 95:5.

Having developed an iterative stereoselective arene-formation for the synthesis of polyaromatics, ${ }^{[43-47]}$ we next tackled the simultaneous formation of two aromatic rings governed by small molecule catalysis. Inspired by the natural biosynthetic pathways to polyketide structures, we became further captivated by the catalytic folding of more complex polycarbonyls. ${ }^{[13-22]}$ Considering the $\beta$-oxygenation pattern of canonical polyketides and the consequential limitations in enzymatic processes, we were intrigued by the prospects of noncanonical polyketide cyclizations that allow the synthesis of products with irregular oxygenation patterns. ${ }^{[48]}$ Interestingly, the required substrates were accessible by a fourfold ozonolysis of biindene precursors that are obtained by an oxidative dimerization of cinnamyl indenes and an indene double bond isomerization with pyrrolidine (Scheme 5). In the course of the biomimetic cyclizations, two viable folding modes proceeding through a twofold 5-(enolexo)-exo-trig ${ }^{[49,50]}$ or the divergent double 6-(enolendo)-exo-trig cyclization give rise to hydropentalenes or the particularly valuable tetra-ortho-substituted atropisomeric biaryls.

Upon exposure to catalytic amounts of a secondary amine that allows for an extended hydrogen-bond network, a twofold areneforming aldol condensation reaction leading to highly enantioenriched biaryl atropisomers was identified (Scheme 6). The scope of the reaction spans from symmetric binaphthyls to complex unsymmetrical or tetrafluorinated derivatives that constitute catalyst precursors of high interest. ${ }^{[48]}$ Gratifyingly, the products emerging from the small molecule-catalyzed noncanonical polyketide cy-

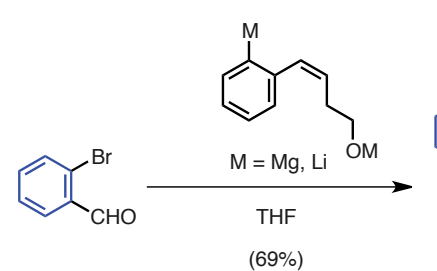

$(69 \%)$

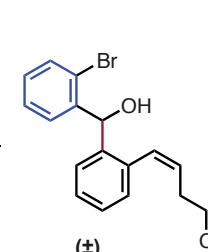

$( \pm)$

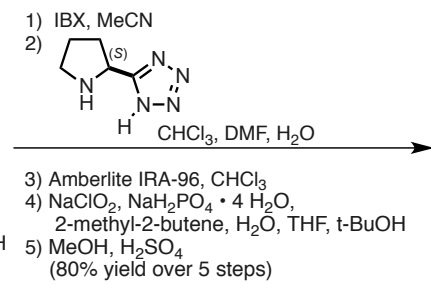

$\mathrm{IBX}, \mathrm{MeCN}$
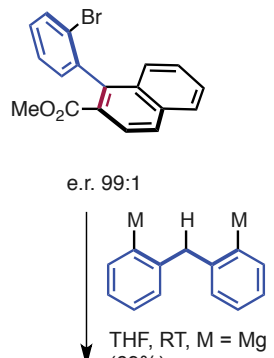

$\nabla_{(69 \%)}$

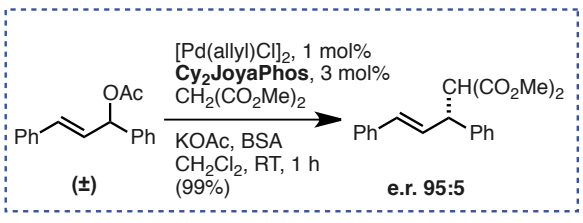

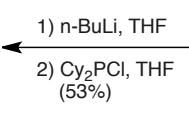

$\mathrm{Cy}_{2}$ JoyaPhos
Scheme 4. Synthesis and benchmarking of the $\mathrm{Cy}_{2}$ JoyaPhos ligand. 
Scheme 5. Catalytic noncanonical polyketide cyclization.

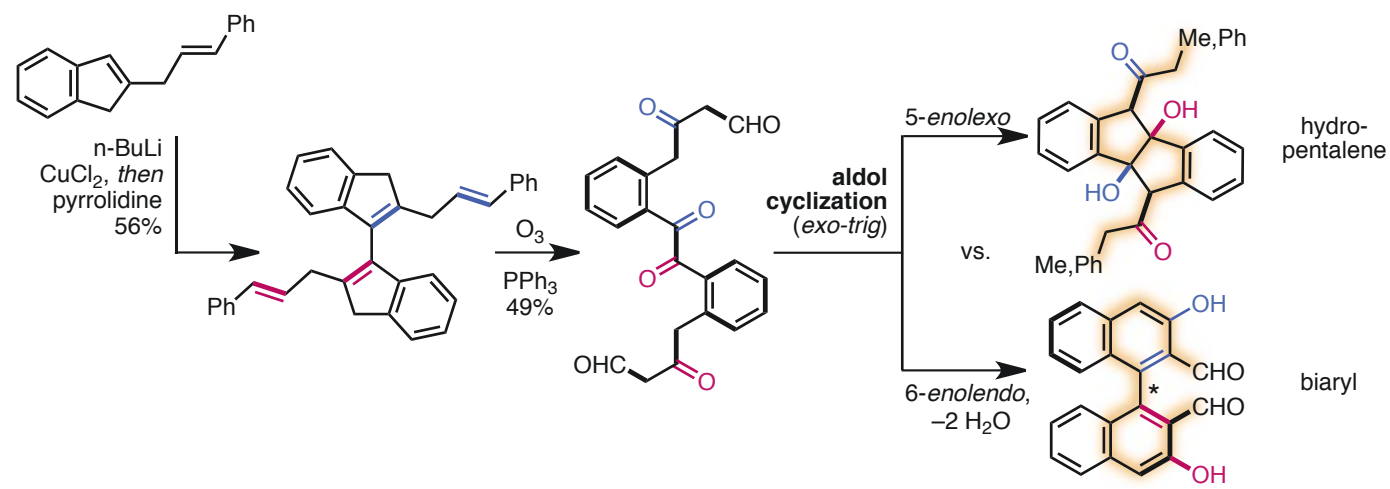

clization serve as particularly useful linchpins and a chiral diene ligand, ${ }^{[51]}$ an enantio-enriched [5] helicene ${ }^{[52]}$ and the Maruoka ion-pairing catalyst ${ }^{[53]}$ were readily obtained.

In conclusion, catalytic cascade reaction inspired by polyketide biosynthesis were found to be particularly versatile for de novo synthesis of polyaromatic compounds. The approach allows the cyclization of canonical as well as noncanonical polyketides to a broad range of stereochemically complex atropisomers. By considering the hidden polyketide pattern in otherwise unrelated polyaromatics, ${ }^{[22]}$ strategies for an efficient construction of valuable products often become discernible. Our ongoing studies focus on stereoselective methods for small-molecule catalyzed polyketide cyclization of native substrates, correlations with enzymatic processes and the simultaneous construction of multiple stereogenic axes.

\section{Acknowledgements}

This extremely joyful and exciting journey is the result of the enthusiasm, creativity, talent, and great teamwork of all group members, for which I (C.S.) am exceptionally thankful. Basel is a truly unique place for chemists and we are very grateful for the stimulating environment and the countless discussion with colleagues in academia and industry. We also gratefully acknowledge the Swiss National Science Foundation, the University of Basel, and the NCCR Molecular Systems Engineering for generous financial support.

[1] R. Ardkhean, D. F. J. Caputo, S. M. Morrow, H. Shi, Y. Xiong, E. A. Anderson, Chem. Soc. Rev. 2016, 45, 1557, doi: 10.1039/C5CS00105F.

[2] A. Eschenmoser, L. Ruzicka, O. Jeger, D. Arigoni, Helv. Chim. Acta 1955, 38, 1890, doi: 10.1002/hlca.19550380728.

[3] G. Stork, A. W. Burgstahler, J. Am. Chem. Soc. 1955, 77, 5068, doi: 10.1021/ ja01624a038.

[4] W. S. Johnson, Angew. Chem. Int. Ed. 1976, 15, 9, doi: 10.1002/ anie. 197600091.

[5] R. A. Yoder, J. N. Johnston, Chem. Rev. 2005, 105, 4730, doi: 10.1021/ cr0406231.

[6] C. N. Ungarean, E. H. Southgate, D. Sarlah, Org. Biomol. Chem. 2016, 14, 5454, doi: 10.1039/С6OB00375C

[7] A. G. M. Barrett, T.-K. Ma, T. Mies, Synthesis 2019, 51, 67, doi: 10.1055/s0037-1610382.

[8] W. S. Johnson, M. F. Semmelhack, M. U. S. Sultanbawa, L. A. Dolak, J. Am. Chem. Soc. 1968, 90, 2994, doi: 10.1021/ja01013a066.

[9] Q. Zhang, K. Tiefenbacher, Nat. Chem. 2015, 7, 197, doi: 10.1038/ nchem.2181 and references cited therein.

[10] C. J. Morten, J. A. Byers, A. R. Van Dyke, I. Vilotijevic, T. F. Jamison, Chem. Soc. Rev. 2009, 38, 3175, doi: 10.1039/B816697H.

[11] H. Liu, S. Lin, K. M. Jacobsen, T. B. Poulsen, Angew. Chem. Int. Ed. 2019, 58, 13630, doi: 10.1002/anie.201812982.

[12] M. Paraja, X. Hao, S. Matile, Angew. Chem. Int. Ed. 2020, 59, doi:10.1002/ anie. 202000681

Scheme 6. Scope of the catalyst-controlled noncanonical polyketide cyclization and applications as diene ligand or ion pairing catalyst.
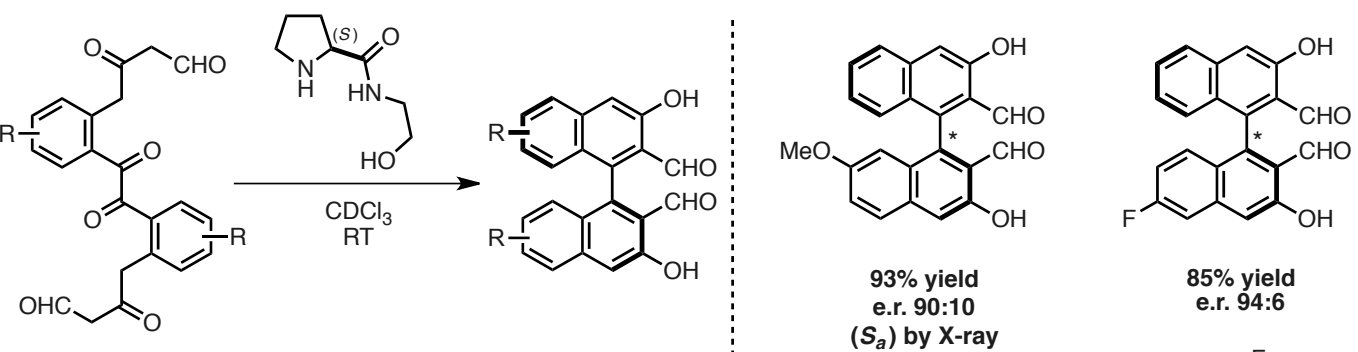

$93 \%$ yield

e.r. 90:10

$\left(S_{a}\right)$ by X-ray
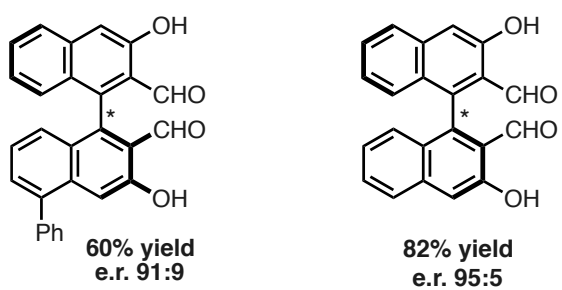

$82 \%$ yield

e.r. $95: 5$

$\left(S_{a}\right)$ by X-ray

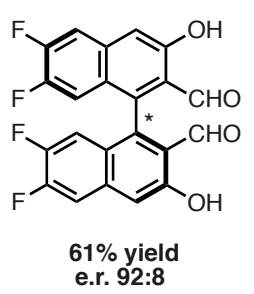

recryst. (e.r. > 99:1), $\mathrm{Tf}_{2} \mathrm{O}, \mathrm{Et}_{3} \mathrm{~N}, \mathrm{CH}_{2} \mathrm{Cl}_{2}$

then $\mathrm{ArB}(\mathrm{OH})_{2}, \mathrm{Pd}(\mathrm{AcO})_{2}, \mathrm{PPh}_{3}, \mathrm{~K}_{2} \mathrm{HPO}_{4}, \mathrm{THF}, 84 \%$ (2 steps)
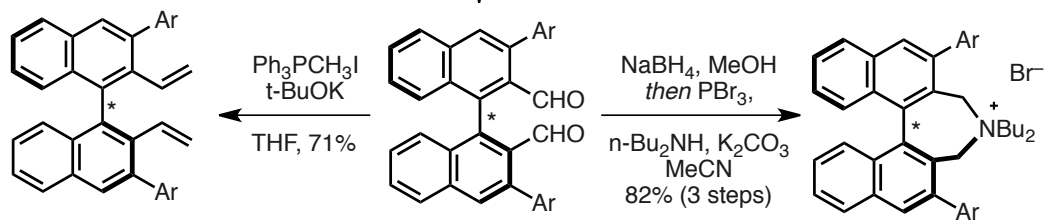

Maruoka ion pairing catalyst 
[13] J. Staunton, K. J. Weissman, Nat. Prod. Rep. 2001, 18, 380, doi: 10.1038/ nrmicro1287.

[14] G. Bringmann, T. F. Noll, T. A. M. Gulder, M. Grüne, M. Dreyer, C. Wilde, F. Pankewitz, M. Hiller, G. D. Payne, A. L. Jones, M. Goodfellow, H.-P. Fiedler, Nat. Chem. Biol. 2006, 2, 429, doi: 10.1038/nchembio805.

[15] C. Hertweck, Angew. Chem. Int. Ed. 2009, 48, 4688, doi: 10.1002/ anie. 200806121

[16] A. Das, C. Khosla, Acc. Chem. Res. 2009, 42, 631, doi: 10.1021/ar8002249.

[17] J. M. Crawford, C. A. Townsend, Nat. Rev. Microbiol. 2010, 8, 879, doi: $10.1038 /$ nrmicro2465.

[18] C. Gil Girol, K. M. Fisch, T. Heinekamp, S. Günther, W. Hüttel, J. Piel, A. A. Brakhage, M. Müller, Angew. Chem. Int. Ed. 2012, 51, 9788, doi: 10.1002/ anie. 201203603 .

[19] H. Aldemir, R. Richarz, T. A. M. Gulder, Angew. Chem. Int. Ed. 2014, 53, 8286, doi: 10.1002/anie.201401075.

[20] L. S. Mazzaferro, W. Hüttel, A. Fries, M. Müller, J. Am. Chem. Soc. 2015, 137, 12289, doi: 10.1021/jacs.5b06776.

[21] H. Muxfeldt, G. Haas, G. Hardtmann, F. Kathawala, J. B. Mooberry, E. Vedejs, J. Am. Chem. Soc. 1979, 101, 689, doi:10.1021/ja00497a035.

[22] V. C. Fäseke, F. C. Raps, C. Sparr, Angew. Chem. Int. Ed. 2020, 59, 6975 doi: 10.1002/anie.201911255.

[23] V. C. Fäseke, R. M. Witzig, A. Link, D. Lotter, C. Sparr, Chimia 2017, 71, 597, doi: 10.2533/chimia.2017.596.

[24] Z. Feng, D. Chakraborty, S. B. Dewell, B. V. B. Reddy, S. F. Brady, J. Am. Chem. Soc. 2012, 134, 2981, doi: 10.1021/ja207662w.

[25] Z. Quin, J. T. Munnoch, R. Devine, N. A. Holmes, R. F. Seipke, K. A. Wilkinson, B. Wilkinson, M. I. Hutchings, Chem. Sci. 2017, 8, 3218, doi: 10.1039/C6SC04265A.

[26] A. Link, C. Sparr, Angew. Chem. Int. Ed. 2014, 53, 5458, doi: 10.1002/ anie. 201402441

[27] V. C. Fäseke, C. Sparr, Angew. Chem. Int. Ed. 2016, 55, 7261, doi: 10.1002/ anie.201602689.

[28] D. Lotter, M. Neuburger, M. Rickhaus, D. Häussinger, C. Sparr, Angew. Chem. Int. Ed. 2016, 55, 2920, doi: 10.1002/anie.201510259.

[29] R. M. Witzig, D. Lotter, V. C. Fäseke, C. Sparr, Chem. Eur. J. 2017, 23, 12960, doi:10.1002/chem.201702471.

[30] J. Clayden, W. J. Moran, P. J. Edwards, S. R. LaPlante, Angew. Chem. Int Ed. 2009, 48, 6398, doi: 10.1002/anie.200901719.

[31] S. H. Watterson, G. V. De Lucca, Q. Shi, C. M. Langevine, Q. Liu, D. G. Batt, M. Beadoin Bertrand, H. Gong, J. Dai, S. Yip, P. Li, D. Sun, D.-R. Wu, C. Wang, Y. Zhang, S. C. Traeger, M. A. Pattoli, S. Skala, L. Cheng, M. T. Obermeier, R. Vickery, L. N. Discenza, C. J. D’Arienzo, Y. Zhang, E. Heimrich, K. M. Gillooly, T. L. Taylor, C. Pulicicchio, K. W. McIntyre, M. A. Galella, A. J. Tebben, J. K. Muckelbauer, C. Chang, R. Rampulla, A. Mathur, L. Salter-Cid, J. C. Barrish, P. H. Carter, A. Fura, J. R. Burke, J. A. Tino, J. Med. Chem. 2016, 59, 9173, doi: 10.1021/acs.jmedchem.6b01088.

[32] K. T. Barrett, A. J. Metrano, P. R. Rablen, S. J. Miller, Nature 2014, 509, 71 , doi: 10.1038/nature13189.

[33] D. Lotter, A. Castrogiovanni, M. Neuburger, C. Sparr, ACS Cent. Sci. 2018, 4, 656, doi: 10.1021/acscentsci.8b00204.
[34] X. Bao, J. Rodriguez, D. Bonne, Angew. Chem. Int. Ed. 2020, 59, in print, doi: 10.1002/anie.202002518

[35] C. S. Hartley, J. He, J. Org. Chem. 2010, 75, 8627, doi: 10.1021/jo1021025.

[36] M. Rickhaus, M. Mayor, M. Juríček, Chem. Soc. Rev. 2016, 45, 1542, doi: 10.1039/C5CS00620A.

[37] M. Kuss-Petermann, O. S. Wenger, J. Am. Chem. Soc. 2016, 138, 1349, doi: $10.1021 /$ jacs.5b11953.

[38] A. Castrogiovanni, P. Herr, C. B. Larsen, X. Guo, C. Sparr, O. S. Wenger, Chem. Eur. J. 2019, 25, 16748, doi: 10.1002/chem.201904771.

[39] S. Malzkuhn, X. Guo, D. Häussinger, O. S. Wenger, J. Phys. Chem. A 2019, 123, 96, doi: 10.1021/acs.jpca.8b11236.

[40] A. Castrogiovanni, D. Lotter, F. R. Bissegger, C. Sparr, Chem. Eur. J. 2020 , 26 , in print.

[41] A. Krasovskiy, P. Knochel, Angew. Chem. Int. Ed. 2004, 43, 3333, doi: 10.1002/anie.200454084.

[42] A. Link, C. Fischer, C. Sparr, Angew. Chem. Int. Ed. 2015, 54, 12163, doi: 10.1002/anie.201505414.

[43] A. Gutnov, B. Heller, C. Fischer, H.-J. Drexler, A. Spannenberg, B. Sundermann, C. Sundermann, Angew. Chem. Int. Ed. 2004, 43, 3795, doi: 10.1002/anie. 200454164.

[44] T. Shibata, T. Fujimoto, K. Yokota, K. Takagi, J. Am. Chem. Soc. 2004, 126, 8382, doi:10.1021/ja048131d.

[45] K. Tanaka, Chem. Asian J. 2009, 4, 508, doi: 10.1002/asia.200800378.

[46] F. Guo, L. C. Konkol, R. J. Thomson, J. Am. Chem. Soc. 2011, 133, 18, doi: $10.1021 /$ ja 108717 r.

[47] A. Link, C. Sparr, Chem. Soc. Rev. 2018, 47, 3804, doi: 10.1039/ C7CS00875A.

[48] R. M. Witzig, V. C. Fäseke, D. Häussinger, C. Sparr, Nat. Catal. 2019, 2, 925, doi:10.1038/s41929-019-0345-0.

[49] J. E. Baldwin, M. J. Lusch, Tetrahedron 1982, 38, 2939, doi: 10.1016/00404020(82)85023-0.

[50] C. Pidathala, L. Hoang, N. Vignola, B. List, Angew. Chem. Int. Ed. 2003, 42 2785, doi: 10.1002/anie.200351266.

[51] Y. Liu, H. Du, J. Am. Chem. Soc. 2013, 135, 6810.

[52] P. Ravat, R. Hinkelmann, D. Steinebrunner, A. Prescimone, I. Bodoky, M Juríček, Org. Lett. 2017, 19, 3707, doi: 10.1021/ja4025808.

[53] S. Shirakawa, K. Maruoka, Angew. Chem. Int. Ed. 2013, 52, 4312, doi: 10.1002/anie.201206835.

\section{License and Terms}

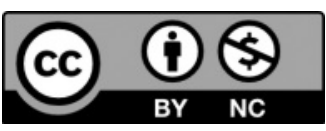

This is an Open Access article under the terms of the Creative Commons Attribution License CC BY_NC 4.0. The material may not be used for commercial purposes.

The license is subject to the CHIMIA terms and conditions: (http:// chimia.ch/component/sppagebuilder/?view=page \&id=12).

The definitive version of this article is the electronic one that can be found at https://doi.org/10.2533/chimia.2020.699 